\title{
The Use of Chemical Methods and Magnetic Field in Conditioning and Dewatering of Digested Sewage Sludge
}

\author{
Tomasz Kamizela, Mariusz Kowalczyk and Iwona Zawieja *D \\ Department of Infrastructure and Environment, Czestochowa University of Technology, Dabrowskiego 69, \\ 42-200 Czestochowa, Poland; tkamizela@is.pcz.czest.pl (T.K.); mkowalczyk@is.pcz.czest.pl (M.K.) \\ * Correspondence: izawieja@is.pcz.czest.pl; Tel.: +48-343-250-917
}

Received: 29 April 2020; Accepted: 3 June 2020; Published: 8 June 2020

\begin{abstract}
This study verified the possibility of sludge conditioning before dewatering using a combination of factors such as iron coagulant, polyelectrolyte, and the magnetic field generated by a solenoid. It was assumed that further conditioning with the magnetic field, leads to the formation of a rigid structure of sludge flocs by the destabilized and flocculated solid phase particles in the sludge (using the conditioning dual chemical method: PIX—polyelectrolyte). The resulting structure can increase the efficiency of sludge cake filtration by reducing sludge compressibility and maintaining the porosity necessary for the flow of removed water through the filter cake. The effects of the exposure of conditioned sludge (after the dual chemical method) to the magnetic field depended on two factors. The first factor was the direction of sludge flow through the magnetic field. This was a key factor in improving the efficiency of sludge conditioning using this method. The sludge flow through the solenoid in the direction opposite to the magnetic field had a strong effect on the particles. The second factor was the rate of sludge flow through the magnetic field. Better results were obtained for a flow rate of $1.0 \mathrm{~L} / \mathrm{min}$ than for pumping sludge through a coil at a rate of $2.0 \mathrm{~L} / \mathrm{min}$. At a flow rate of $1.0 \mathrm{~L} / \mathrm{min}$, the exposure time of the sludge to the magnetic field was $6.6 \mathrm{~s}$. Too high a flow rate may lead to the deterioration of filtration efficiency by adverse changes in the structure of sludge flocs. This may be due to the mechanical destruction of the flocs structure of sludge by a too turbulent flow.
\end{abstract}

Keywords: digested sludge; conditioning; polyelectrolyte; ferric coagulant; magnetic field; dewatering

\section{Introduction}

Nowadays, the treatment of sludge generated in wastewater treatment plants represents a serious technological challenge. Obtaining a sufficient degree of sludge dewatering determines the opportunity of its use for energy generation and in agriculture. The major challenge of sludge disposal is to reduce its hydration. The water content in sludge and, consequently, its volume, determine the required capacity of the equipment and the possibilities of its transport, composting or combustion. The main processes that reduce sludge hydration include thickening and dewatering. Reducing hydration requires not only appropriate equipment but also specific dosing of conditioning agents. Without the commonly used polyelectrolytes, the efficiency of sewage sludge dewatering would be significantly limited. Sludge conditioning using polyelectrolytes leads to the improvement in sewage sludge dewatering [1-5].

Many conditioning methods are based on the use of various iron-containing substances, which cause coagulation and a flocculation effect. Wang et al. [6] used a ferric hydroxide gel for conditioning. Liu et al. [7] tested an alkaline ferrate solution containing $\mathrm{Fe}(\mathrm{VI})$ and $\mathrm{KOH}$. Zhen et al. [8] proposed a sequential dosing of Fe(II)-activated persulfate $\left(\mathrm{S}_{2} \mathrm{O}_{8}\right)$ as an effective method of sludge 
dewatering. This method of sludge conditioning was improved by Shi et al. [9] through the addition of phosphogypsum.

It is also possible to use more conventional conditioning. Some wastewater treatment plants in Poland are testing a dual chemical method, which is based on the sequence of dosing iron coagulant (PIX) followed by polyelectrolyte (dual chemical method: PIX + polyelectrolyte). In general, the coagulant PIX is only used to neutralize the surface charge of particles, with polyelectrolyte used as a crosslinking agent enabling particle agglomeration. The purpose of this method is to produce the densest and least porous and water-binding flocs [10-12].

Due to the content of the ferromagnetic material (iron) in the coagulant, the dual chemical method can be extended by the exposure of sludge to the magnetic field.

Studies using the magnetic field in wastewater and sewage sludge technology have focused mainly on issues related to the intensification of biological wastewater treatment [13-15]. Biodiversity of microorganisms in activated sludge biomass exposed to the magnetic field has also been analyzed [16,17].

As a conditioning factor, the electromagnetic field has also been tested for the effective sewage sludge dewatering, both independently and combined with dosing chemicals containing ferromagnetic substances such as iron coagulants $[18,19]$.

Despite extensive knowledge in the field of magnetization of environmental samples and the use of the magnetic field in bioreactor engineering, many aspects require further research. The exposure of various types of environmental samples to the magnetic field can be achieved in two ways, using permanent magnets $[14,15]$ and an induction coil $[13,18]$. In the former method, positioning the magnets (changing the distance) is required to obtain appropriate induction values. In the latter, however, it is necessary to change power supply conditions and the solenoid design.

Previous studies have verified the possibility of sludge conditioning before dewatering using a combination of iron coagulant, polyelectrolyte, and magnetic field with an induction of $0.04 \mathrm{~T}$ generated by a solenoid [18]. The induction of $0.04 \mathrm{~T}$ used in the study corresponds to the values used by other authors $[13,14,16,17]$, whose primary aim was to intensify biochemical transformations. However, to achieve sludge dewatering, it was recommended to use magnetic induction values higher than $40 \mathrm{mT}$ [18].

The aim of the present study was to confirm the possibility of using a dual chemical method of conditioning of digested sludge, which intensifies solid phase separation processes compared to the polymeric method. The tests were aimed to examine the possibilities of using the magnetic field with an induction of $90 \mathrm{mT}$ as a factor improving the technological properties of chemically pre-conditioned sludge.

\section{Research Methodology}

\subsection{Materials}

Digested sludge, which was the main substrate of the research (after the methane fermentation process) was sampled from the heat exchanger installation of the wastewater treatment plant (WWTP) in Czestochowa, Poland. The average daily wastewater inflow volume to the treatment plant is $45,000 \mathrm{~m}^{3} / \mathrm{d}$. The WWTP operates based on the UCT (University of Cape Town) technological system. Total solids (TS) and volatile solids (VS) of digested sludge were $18.8 \mathrm{~g} / \mathrm{L}( \pm 3.2 \mathrm{~g} / \mathrm{L})$ and $9.0 \mathrm{~g} / \mathrm{L}$ $( \pm 1.6 \mathrm{~g} / \mathrm{L})$, respectively. The $\mathrm{pH}$ of the collected sludge ranged from 7.2 to 7.8 , whereas alkalinity was $3656 \mathrm{mg} \mathrm{CaCO} / \mathrm{L}( \pm 532 \mathrm{mg} \mathrm{CaCO} / / \mathrm{L})$.

The inorganic ferric coagulant Kemira Kemipol PIX-113 (Kemipol, Police, Poland) and polyelectrolyte Superfloc C-494 (Kemipol, Police, Poland) were used. PIX-113 is based on iron(III) sulfate with a total iron content of nearly $12 \%$. The concentration of Superfloc C-494 (medium-cationic polyelectrolyte) was $0.1 \%$. The coagulant PIX-113 was dosed at a constant volume of $4 \mathrm{~mL} / \mathrm{L}$ $(0.32 \pm 0.05 \mathrm{~kg} / \mathrm{kg} \mathrm{TS})$, which corresponded to an iron dose of about $39.0 \mathrm{~g} / \mathrm{kg}$ TS. The dose of $4 \mathrm{~mL} / \mathrm{L}$ of coagulant PIX-113 and its concentration of $0.1 \%$ were derived from previous studies [19]. 


\subsection{Experimental Apparatus for Sludge Conditioning in the Magnetic Field}

Conditioned sludge was exposed to the magnetic field during flow. The sludge was pumped through the induction coil to a tank (glass vessel) using a peristaltic pump (Figure 1). The coil generated a magnetic field with maximal induction of $90 \mathrm{mT}$ (at $4 \mathrm{~A}$ ). The length of the solenoid was $220 \mathrm{~mm}$ the inner diameter of the bobbin was $33.0 \mathrm{~mm}$, the wire diameter was $1.15 \mathrm{~mm}$, the number of turns was 4388 , and current intensity was $4.0 \mathrm{~A}$. A PVC pipe (internal diameter of $25.0 \mathrm{~mm}$ ) was placed inside the coil. The conditioned sludge was pumped through the PVC pipe using a peristaltic pump.
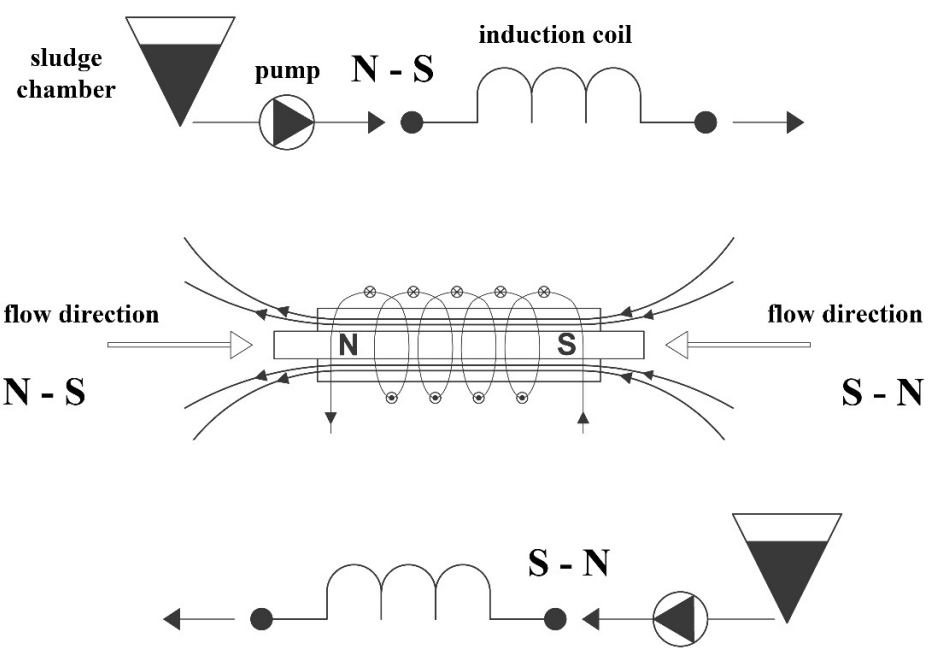

Figure 1. The experimental apparatus for sludge conditioning in the magnetic field [20].

The peristaltic pump pumped the conditioned sludge at two flow rates: $\mathrm{Q}_{1}=1.0 \mathrm{~L} / \mathrm{min}$ and $\mathrm{Q}_{2}=2.0 \mathrm{~L} / \mathrm{min}$. Based on the flow rate $\left(\mathrm{Q}_{1}\right.$ and $\left.\mathrm{Q}_{2}\right)$ and the volume of the pipe calculated based on the length of the coil $(\approx 110 \mathrm{~mL})$, the exposure time of the sludge to the magnetic field was calculated as $\mathrm{t}_{1}=6.6 \mathrm{~s}$ and $\mathrm{t}_{2}=3.3 \mathrm{~s}$, respectively.

Two combinations of sludge flow through the coil were used: In the direction of the magnetic field lines (flow S-N) and opposite to the direction of the magnetic field lines (flow N-S).

Calculations of magnetic induction (based on geometric, material, and electrical specifications of the coil) were made using the Comsol Multiphysics 5.2a software (Jaarbeurs, Utrecht, The Netherlands [21] (Figure 2). The magnetic field induction inside the solenoid was measured using a Teslameter Phywe sensor (Wuntronic $\mathrm{GmbH}$, Munich, Germany) and was consistent with the calculations.

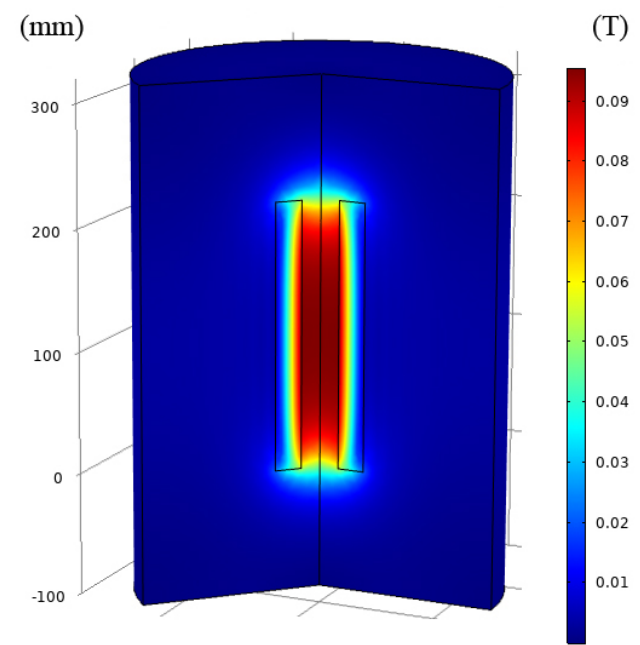

Figure 2. The distribution of the magnetic field induction in a solenoid. 


\subsection{Stages of Research}

The research was divided into four stages, including nine combinations of different types and parameters of conditioning (Table 1).

Table 1. Research combinations for sludge conditioning.

\begin{tabular}{cccccc}
\hline Combination & $\begin{array}{c}\text { PIX-113 Dose, } \\
\mathbf{k g} / \mathbf{k g} \text { TS }\end{array}$ & $\begin{array}{c}\text { Polyelectrolyte } \\
\text { C-494 Dose, } \mathbf{g} / \mathbf{k g} \text { TS }\end{array}$ & $\begin{array}{c}\text { Magnetic Field } \\
\text { Direction }\end{array}$ & $\begin{array}{c}\text { Exposure } \\
\text { Time, } \mathbf{s}\end{array}$ \\
\hline D & Non-prepared sludge & - & - & - & - \\
\hline A & Sludge conditioned only with & - & 4.5 & - & - \\
B & polyelectrolyte & - & 3.6 & - & - \\
\hline C & Dual chemical conditioning & 0.32 & 4.5 & - & - \\
D & & 0.32 & 3.6 & flow S-N & $\mathrm{t}_{1}=6.6$ \\
\hline E & & 0.32 & 3.6 & flow S-N & $\mathrm{t}_{2}=3.3$ \\
F & Sludge after dual conditioning & 0.32 & 3.6 & flow N-S & $\mathrm{t}_{1}=6.6$ \\
G & exposed to the magnetic field & 0.32 & 3.6 & flow N-S & $\mathrm{t}_{2}=3.3$ \\
H & & 0.32 & 3.6 & &
\end{tabular}

The optimal dose of polyelectrolyte C-494 was determined using the capillary suction time $(\mathrm{CSK})$ test and was $4.5 \pm 0.31 \mathrm{~g} / \mathrm{kg}$ TS $(\mathrm{CSK}=106 \mathrm{~s})$. A polyelectrolyte C-494 dose reduced by $20 \%$ (as in [18]) compared to the optimal dose was also used in the study. The reduced dose was $3.6 \pm 0.42 \mathrm{~g} / \mathrm{kg}$ TS $($ CSK $=182 \mathrm{~s})$. The reduction of the polyelectrolyte dose resulted from the use of additional conditioning factors, i.e., mineral coagulant and the magnetic field.

Mixing of the tested sludge $(1 \mathrm{~L})$ was carried out using a $10.0 \mathrm{~cm}$ diameter paddle stirrer in a glass vessel. In combinations $A$ and $B$, the sludge was mixed with the polymer for $20 \mathrm{~s}$ at $250 \mathrm{rpm}$ $\left(G=609 \mathrm{~s}^{-1}\right)$. In combinations $C$ and $D$, the samples were mixed, first for $60 \mathrm{~s}$ with the coagulant PIX-113 at $400 \mathrm{rpm}\left(\mathrm{G}=1226 \mathrm{~s}^{-1}\right)$, and next with the polyelectrolyte $(20 \mathrm{~s}, 250 \mathrm{rpm})$. In combinations $\mathrm{E}$ to $\mathrm{H}$, the conditioning procedure was the same as for combinations $\mathrm{C}$ and $\mathrm{D}$, with the sludge pumped through the coil immediately after chemical conditioning.

\subsection{Analysis}

Dry solids (TS), volatile solids (VS), total Kjeldahl nitrogen (TKN), and ammonium nitrogen $\left(\mathrm{NH}_{4}{ }^{+}-\mathrm{N}\right)$ were measured by means of standard methods of water and wastewater testing [22].

To characterize filtration properties of the conditioned sludge, measurements of capillary suction time (CST), specific resistance to filtration (r), and coefficient of compressibility (s) were performed according to European and Polish standard procedures [23-25].

Rheological parameters were determined using the RC20 rheometer, with the shear rate of $0-200 \mathrm{~s}^{-1}$ for $120 \mathrm{~s}$. Three models were used to determine the rheological parameters of the sludge. The simplest mathematical rheological model used to describe the flow curve is the Ostwald-de Waele power model [26]:

$$
\tau=\mathrm{k} \cdot(\gamma)^{\mathrm{n}}
$$

where $\mathrm{k}$ is the constant termed consistency coefficient, Pa.s; $\gamma$ is the shear rate, $\mathrm{s}^{-1}$; and $\mathrm{n}$ is the yield exponent.

In the Bingham model, fluids flow only after applying the shear stress $\tau_{0}$, and, for smaller stress, they behave as a plastic solid:

$$
\tau=\tau_{\mathrm{o}}+\eta_{\mathrm{pl}} \cdot \gamma
$$

where $\tau_{\mathrm{o}}$ is the yield stress, $\mathrm{Pa}$ and $\eta_{\mathrm{pl}}$ is the plastic viscosity, Pa.s.

Herschel-Bulkley models are mostly composed of three parameters:

$$
\tau=\tau_{\mathrm{o}}+\mathrm{K} \cdot(\gamma)^{\mathrm{n}}
$$


where $\tau_{\mathrm{o}}$ is the yield stress, $\mathrm{Pa} ; \mathrm{K}$ is the rheological parameter of the model; and $\mathrm{n}$ is the yield exponent.

A hysteresis loop was used to determine the thixotropic properties of the tested sludge. The sludge was sheared at a gradually increasing shear rate which then decreased to zero. The area bounded by the curves is a measure of the thixotropic properties of the fluid. The area inside the loop is a measure of the amount of energy that the sludge has accumulated during shearing [6]. They are represented by an example:

$$
\mathrm{T}=\mathrm{T}^{\prime}-\mathrm{T}^{\prime \prime}
$$

where $\mathrm{T}$ is the area of the hysteresis loop, $\mathrm{Pa} \cdot \mathrm{s}^{-1} ; \mathrm{T}^{\prime}$ is the area of the upper flow curve, $\mathrm{Pa} \cdot \mathrm{s}^{-1}$; and $\mathrm{T}^{\prime \prime}$ is the area of the lower flow curve, $\mathrm{Pa} \cdot \mathrm{s}^{-1}$.

The chemical oxygen demand (COD) in the supernatant was measured using Hach test tubes and a Hach Lange DR 5000 spectrophotometer (HACH LANGE Sp. z o.o., Wrocław, Poland). Supernatant turbidity (T) was measured using a Hach TL23 turbidimeter (HACH LANGE Sp. z o.o., Wrocław, Poland). The total organic carbon (TOC) in the supernatant was analyzed in accordance with the differential method using a TOC analyzer (Analytik Jena multi N/C 3100, Jena, Germany). Prior to the measurement of COD in the supernatant, the samples of conditioned sludge were centrifuged for $3 \mathrm{~min}$ at $3500 \mathrm{rcf}$. Before TKN, $\mathrm{NH}_{4}{ }^{+}-\mathrm{N}$, and TOC measurements, supernatant samples were centrifuged (15 min at $12,100 \mathrm{rcf})$ and filtered through a membrane filter $(0.45 \mu \mathrm{m}$, cellulose acetate, Machery-Nagel, Dueren, Germany). Inductively coupled plasma optical emission spectroscopy (ICP-OES) was used to determine concentrations of iron and phosphorus [27].

\subsection{Statistical Analysis}

Statistical analysis was carried out using the STATISTICA software (STATISTICA 13.3, TIBCO Software Inc., Palo Alto, CA, USA). The effect of conditioning combinations on sludge parameters was analyzed using the ANOVA analysis of variance (homogeneity of variances). Tukey's honest significant difference (HSD) post hoc test was used in the case of statistically significant data $(p<0.05)$. The statistical analysis aimed to determine whether the applied treatment method had a statistically significant effect (different letters a, b, c, d, e in the figures) on parameters measured in the research. Results marked with the same letter in the specified group are not statistically significant (no difference between values).

\section{Results and Discussion}

\subsection{Filtration Properties}

The basic evaluation of susceptibility to dewatering of the conditioned sludge is based on the results of capillary suction time (CST) measurement (Figure 3). The use of polyelectrolyte (combinations $\mathrm{A}$ and $\mathrm{B}$ ) in sludge conditioning led to more than 10 times faster sludge dewatering compared to untreated sludge (combination 0 ). The most effective method of sludge preparation was the dual chemical conditioning method (combinations $C$ and $D$ ). The exposure of dually conditioned sludge to the magnetic field did not significantly change the dewatering capacity.

However, it was found that the direction of sludge flow through the coil and the flow rate affected the capillary suction rate. The most appropriate sludge conditioning in the magnetic field was observed for the sludge flow opposite to the direction of the magnetic field lines (combinations $\mathrm{G}$ and $\mathrm{H}$ ) and a low flow rate of $Q=1 \mathrm{~L} / \mathrm{min}$ (combination $\mathrm{G}$ ).

Trends of changes in specific resistance to filtration of the conditioned sludge were similar to changes in the capillary suction time (Figure 4). The dual method (C and D) was a highly satisfactory method of sludge conditioning. The coagulation and flocculation of sludge with the coagulant and polyelectrolyte and their further exposure to the magnetic field may be the preferred solution. The lowest specific resistance to filtration $\left(2.1 \times 10^{12} \mathrm{~m} / \mathrm{kg}\right)$ was found in the sludge exposed to the magnetic field at a flow rate of $\mathrm{Q}_{1}=1.0 \mathrm{~L} / \mathrm{min}$ and $\mathrm{N}-\mathrm{S}$ direction (combination $\mathrm{G}$ ). 


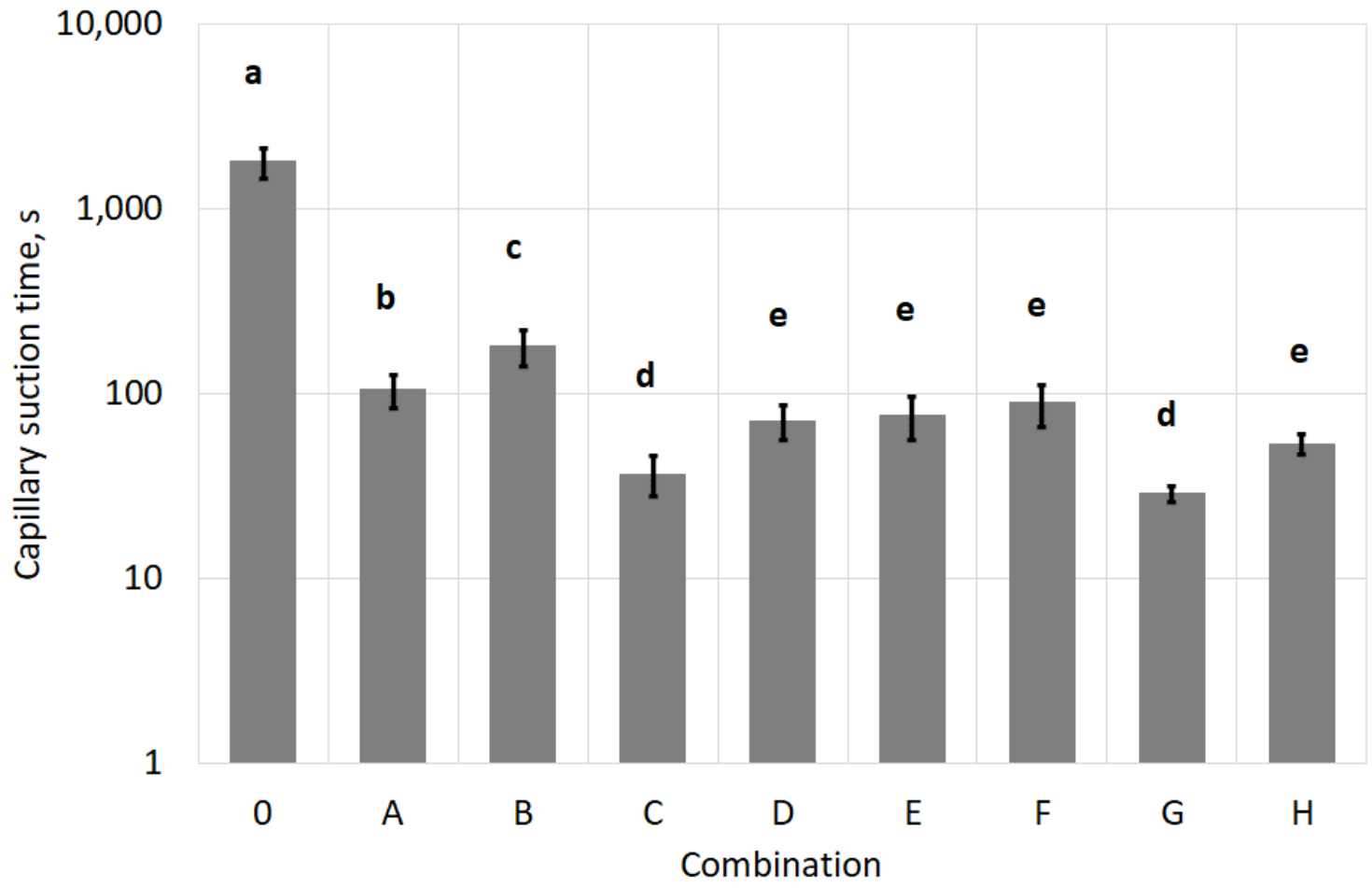

Figure 3. Effect of the method of sludge conditioning on capillary suction time.

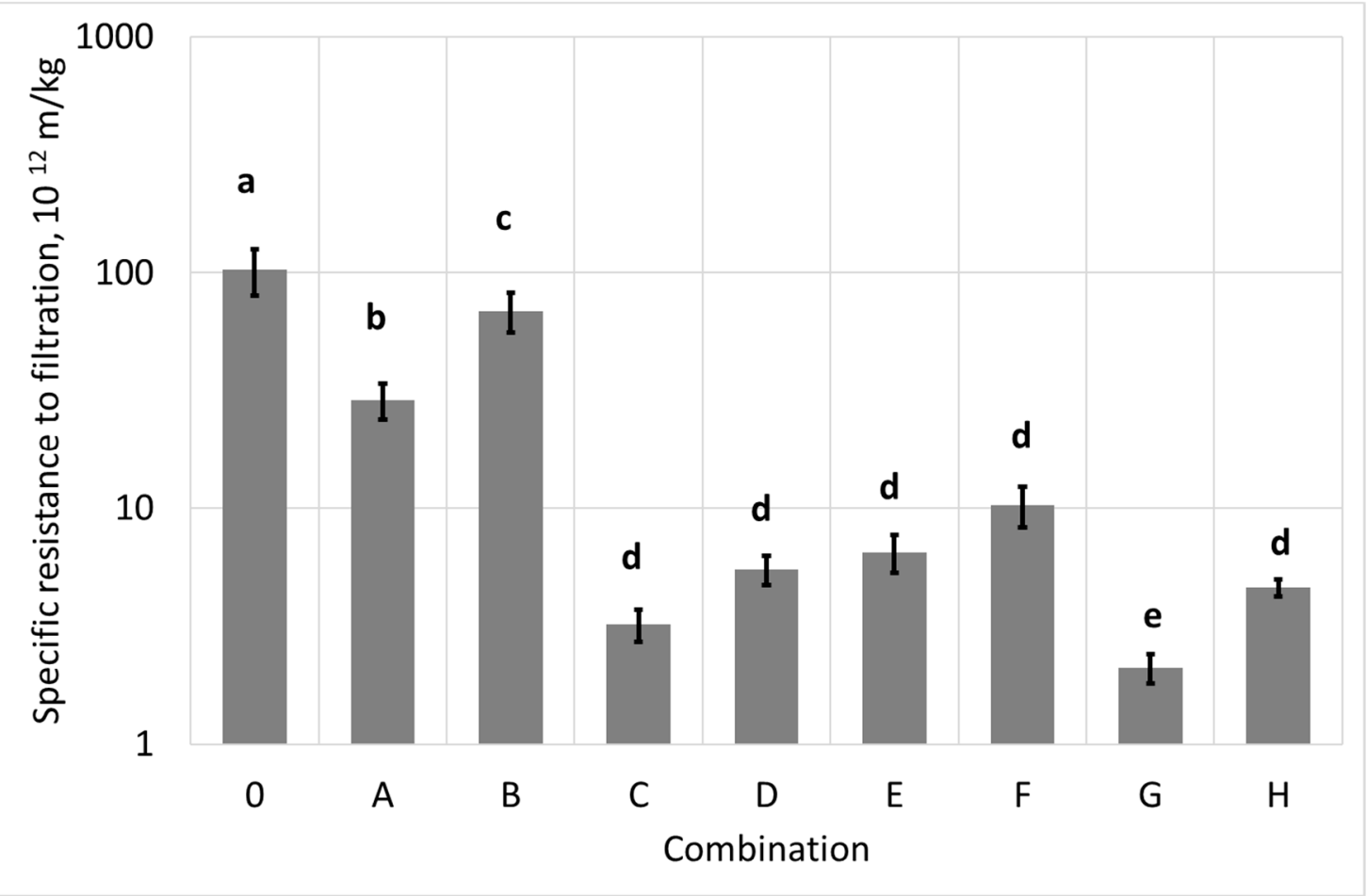

Figure 4. Specific resistance to filtration (conditioned sludge).

During sludge dewatering using a pressure filter press, a decrease in sludge filterability was observed, along with an increase in the filtration pressure (Figure 5). This effect was independent of the conditioning combination. With regard to dewatering efficiency, the use of dual conditioning $(\mathrm{C}$ and D) was more beneficial than conditioning only with the polyelectrolyte (A and B). However, sludge 
filtration at a pressure higher than $0.3 \mathrm{MPa}$ resulted in exceeding the filterability limit (the sludge with a specific resistance of less than $5.0 \times 10^{12} \mathrm{~m} / \mathrm{kg}$ is considered susceptible to filtration [23]). For example, the specific resistance to filtration of the sludge prepared using the dual chemical method (C) and filtered at a pressure of $0.3 \mathrm{MPa}$ was $0.07 \times 10^{13} \mathrm{~m} / \mathrm{kg}$, whereas at a pressure of $0.7 \mathrm{MPa}$, the resistance increased 20 times $\left(\mathrm{r}=1.43 \times 10^{13} \mathrm{~m} / \mathrm{kg}\right)$. The advantage of triple conditioning (coagulant-polyelectrolyte-magnetic field) over other methods of sludge preparation was only significant in the case of the combination $G\left(r=0.03 \times 10^{12} \mathrm{~m} / \mathrm{kg}\right)$. The specific resistance of filtration of the sludge conditioned using the combinations $\mathrm{E}, \mathrm{F}$, and $\mathrm{H}$ was close to the level characteristic for the combination D.

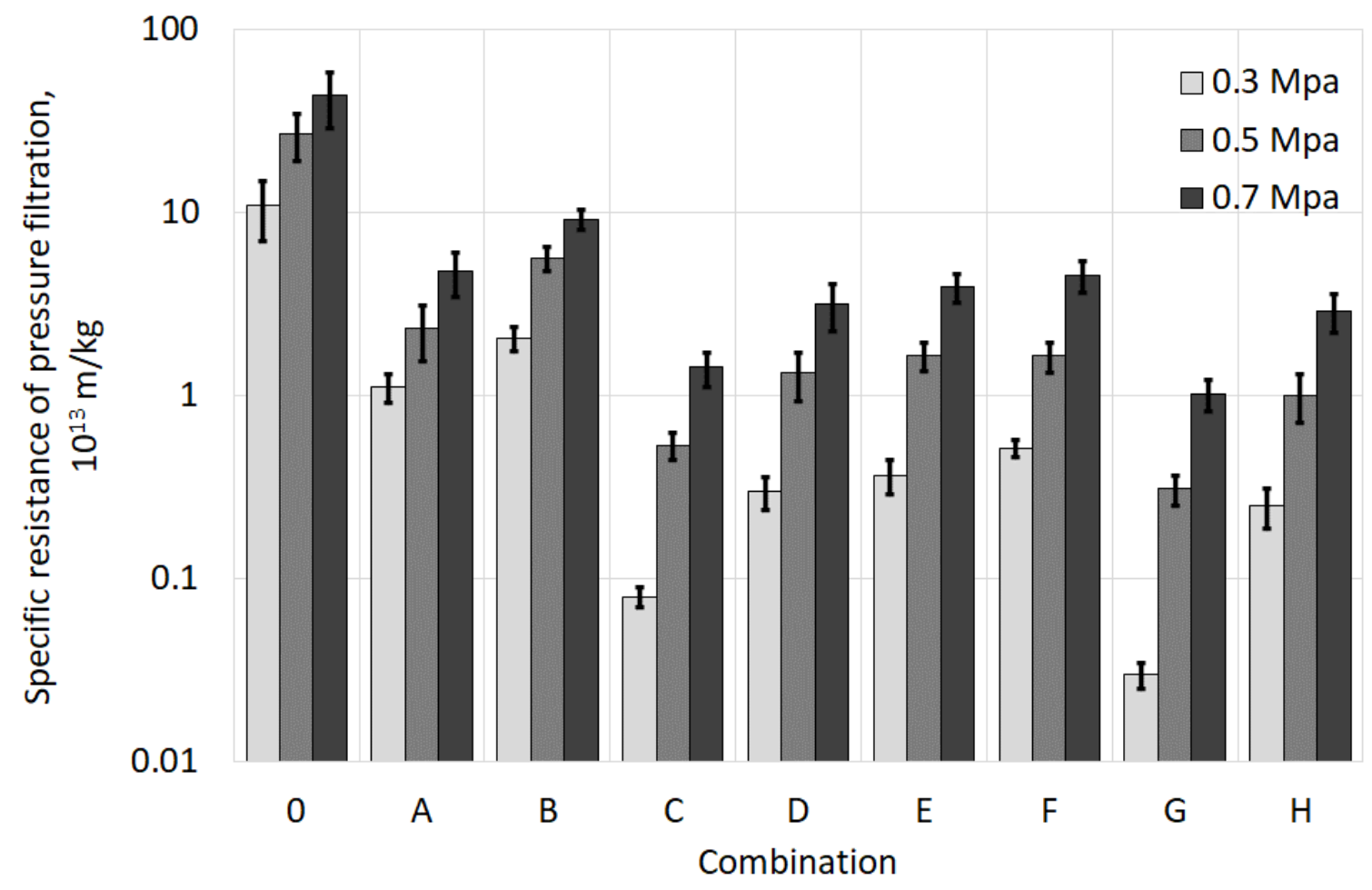

Figure 5. Specific resistance to filtration of pressure-filtered sludge samples.

Pressure filtration data compiled in the $\mathrm{r} / \mathrm{P}$ coordinate system were used to calculate the compressibility factor. In accordance with the standard PN-EN 14701-3 [23], the values of the sludge compressibility coefficient higher than $\mathrm{s}=1$ mean a disproportionate increase in resistance to filtration compared to the increase in pressure. The lowest compressibility coefficients were determined for the untreated sludge and polyelectrolyte-conditioned sludge $(s=1.7-1.8)$ (Table 2). Sludge conditioning with the dual method (C, D) and magnetic field (E, F, H) increased the compressibility factor to 2.8-3.4. The maximum compressibility factor was 4.2 for the sludge conditioned in the magnetic field during the exposure for $6.6 \mathrm{~s}$ and in the opposite direction to the magnetic field lines $(\mathrm{G})$.

Table 2. Sludge compressibility factor depending on the combination of sludge conditioning.

\begin{tabular}{ccccccccc}
\hline \multicolumn{7}{c}{ Combination of Sludge Conditioning/Compressibility Factor } \\
\hline $\mathbf{0}$ & $\mathbf{A}$ & $\mathbf{B}$ & $\mathbf{C}$ & $\mathbf{D}$ & $\mathbf{E}$ & $\mathbf{F}$ & $\mathbf{G}$ & $\mathbf{H}$ \\
\hline $1.7 \pm 0.3$ & $1.7 \pm 0.2$ & $1.8 \pm 0.4$ & $3.4 \pm 0.5$ & $2.8 \pm 0.3$ & $2.8 \pm 0.4$ & $2.5 \pm 0.5$ & $4.2 \pm 0.2$ & $2.7 \pm 0.3$ \\
$\mathrm{a}$ & $\mathrm{a}$ & $\mathrm{a}$ & $\mathrm{b}$ & $\mathrm{c}$ & $\mathrm{c}$ & $\mathrm{c}$ & $\mathrm{d}$ & $\mathrm{c}$ \\
\hline
\end{tabular}

\subsection{Rheological Properties}

Deformation of the solid phase particles during filtration and their closer packing in the filter cake (which limits the filtrate flow) is a normal phenomenon. Therefore, high pressures should be 
avoided in the dewatering of a very compressible sludge. The analysis of the specific resistance to filtration during pressure sludge dewatering revealed that the pressure of $0.3 \mathrm{MPa}$ was the limit of acceptable sludge filterability. This method of sludge conditioning did not have a significant effect on the filtration pressure. Dual conditioning of the sludge including the exposure to the magnetic field supports dewatering provided that low filtration pressures are used.

The main relationship found during rheological measurements was a rapid increase in sludge viscosity up to a shear rate of $20 \mathrm{~s}^{-1}$, followed by a slow decrease in viscosity at higher shear rates (Figure 6). The sludge shearing process caused its structure to break down. At shear rates of above $100 \mathrm{~s}^{-1}$, a dynamic equilibrium is established and viscosity changes are negligible. The highest viscosity was recorded for the sludge conditioned using combination $\mathrm{G}$ for the method of its conditioning at a shear rate of $20 \mathrm{~s}^{-1}$. The sludge conditioned by the dual chemical method and magnetic field using a flow rate of $1.0 \mathrm{~L} / \mathrm{min}$ in the direction opposite to the magnetic field lines $(\mathrm{G})$ was also characterized by the highest values of shear stress. For this combination, at a shear rate of $200 \mathrm{~s}^{-1}$, shear stress was 6.993 Pa (Figure 6).

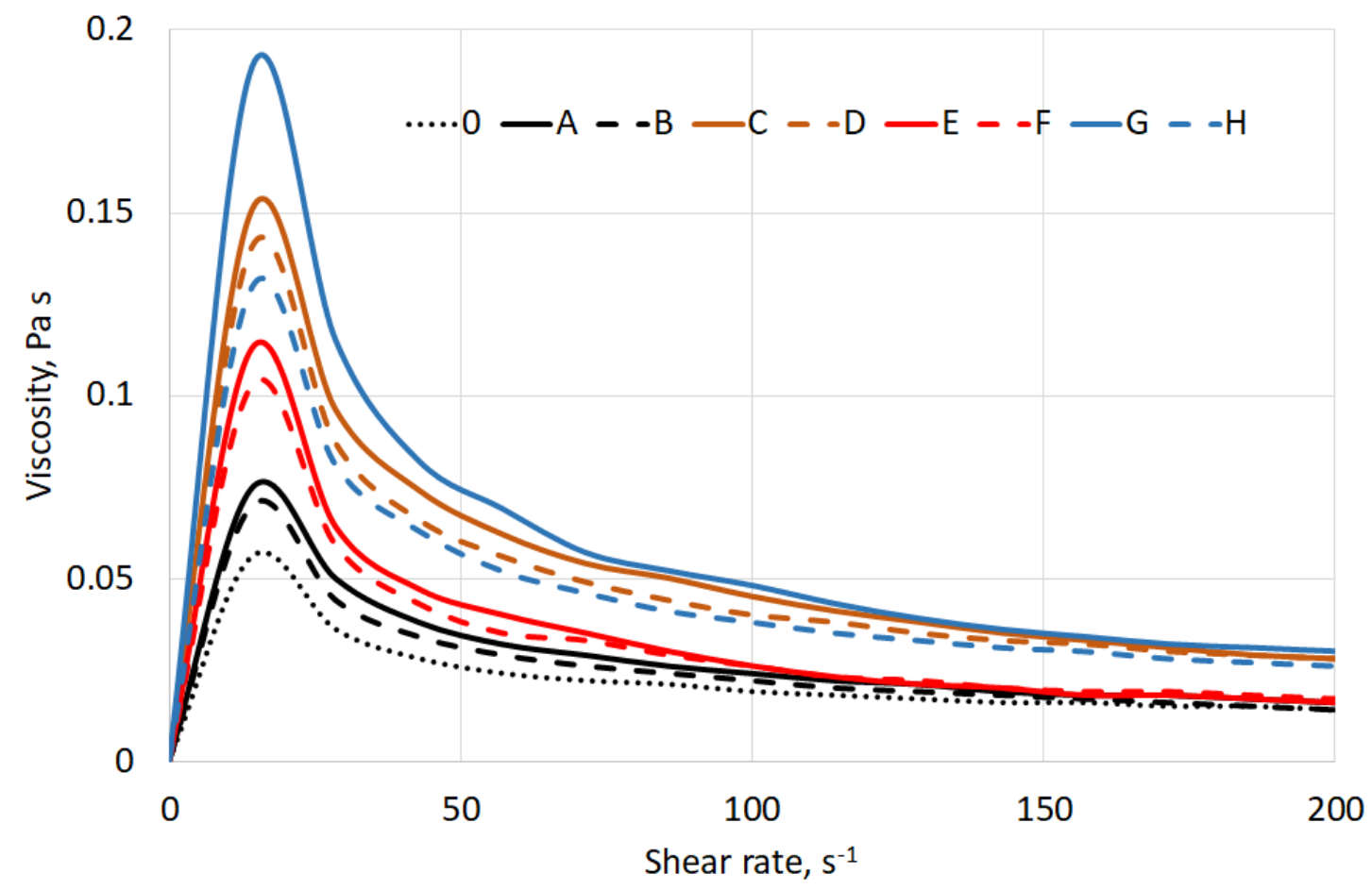

Figure 6. Sludge viscosity versus shear rate and conditioning combination.

Two groups can be distinguished based on the measurements of viscosity and shear stress versus shear rate (Figure 7). The first is a group of conditioning combinations G, C, D, and H with higher values of viscosity and shear stress. These methods of conditioning affected the increase in resistance to shearing forces. The second group is conditioning combinations: $0, \mathrm{~A}, \mathrm{~B}, \mathrm{E}, \mathrm{F}$. Both groups can be classified as shear-thinning fluids $(\mathrm{n}<1)$.

The analysis of rheological models confirmed that all the samples of tested sludge were shear-thinning fluids, with this phenomenon mostly observed for the sludge conditioned in combinations $\mathrm{C}$ to $\mathrm{H}$ (Table 3, Ostwald de Waele). The consistency coefficient describing viscosity of the substrate confirms the increase in sludge viscosity following conditioning, especially in combinations G, C, D, and H (Ostwald de Waele model, combination G, k=0.961). According to the Herschley-Bulkley model, the yield stress of the tested sludge ranged from $0.257 \mathrm{~Pa}(\mathrm{~A})$ to $1.538(\mathrm{G})$. The high yield stress of a dually conditioned sludge $(C, D)$ exposed to the magnetic field $(G, H)$ may be due to the shear-resistant sludge structure, especially after dosing of the coagulant PIX. 


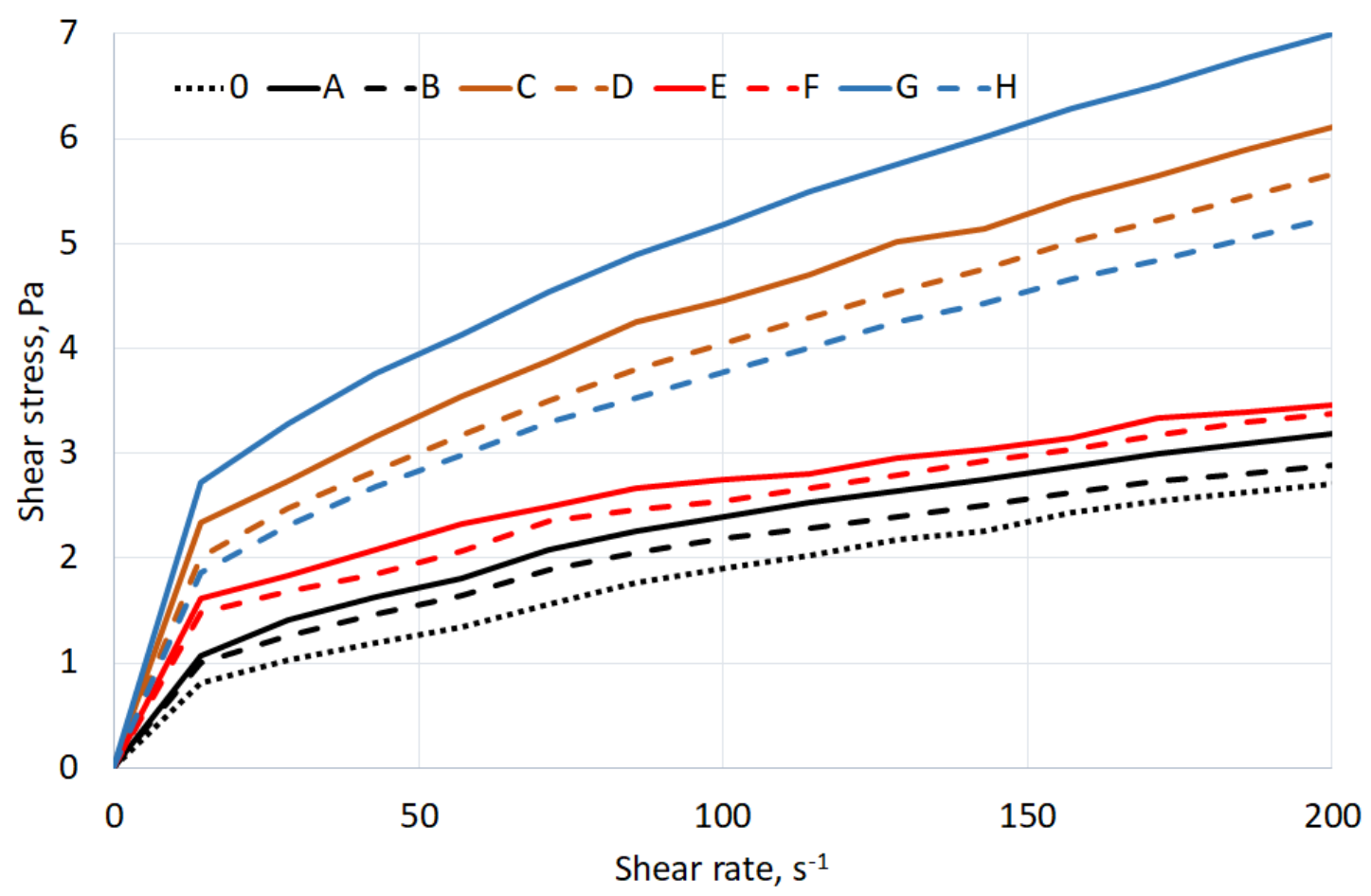

Figure 7. Sludge shear stress versus shear rate and conditioning combination.

Table 3. Parameters of selected rheological models of the tested sludge.

\begin{tabular}{ccccccccccc}
\hline \multirow{2}{*}{ Model/Parameter } & \multicolumn{10}{c}{ Combination } \\
\cline { 2 - 11 } & & $\mathbf{0}$ & $\mathbf{A}$ & $\mathbf{B}$ & $\mathbf{C}$ & $\mathbf{D}$ & $\mathbf{E}$ & $\mathbf{F}$ & $\mathbf{G}$ & $\mathbf{H}$ \\
\hline \multirow{5}{*}{ Sstwald de Waele } & $\mathrm{k}$ & 0.195 & 0.344 & 0.316 & 0.782 & 0.724 & 0.567 & 0.525 & 0.961 & 0.610 \\
& $\mathrm{n}$ & 0.498 & 0.420 & 0.418 & 0.260 & 0.398 & 0.331 & 0.321 & 0.369 & 0.400 \\
& $\mathrm{~B}$ & 0.989 & 0.998 & 0.997 & 0.996 & 0.982 & 0.986 & 0.936 & 0.993 & 0.994 \\
& $\mathrm{~S}$ & 0.071 & 0.026 & 0.033 & 0.075 & 0.066 & 0.198 & 0.137 & 0.117 & 0.084 \\
\hline \multirow{5}{*}{ Bingham } & $\tau_{0}$ & 0.568 & 0.893 & 0.810 & 1.739 & 1.497 & 1.119 & 1.030 & 2.113 & 1.254 \\
& $\mathrm{n}_{\mathrm{pl}}$ & 0.012 & 0.013 & 0.012 & 0.024 & 0.011 & 0.013 & 0.011 & 0.027 & 0.021 \\
& $\mathrm{~B}$ & 0.948 & 0.893 & 0.885 & 0.882 & 0.734 & 0.839 & 0.806 & 0.969 & 0.891 \\
& $\mathrm{~S}$ & 0.189 & 0.309 & 0.28 & 0.582 & 0.428 & 0.366 & 0.354 & 0.695 & 0.481 \\
\hline \multirow{5}{*}{ Herschley-Bulkley } & $\tau_{0}$ & 0.257 & 0.466 & 0.378 & 1.297 & 1.043 & 0.692 & 0.666 & 1.538 & 0.996 \\
& $\mathrm{~K}_{\mathrm{n}}$ & 0.045 & 0.471 & 0.159 & 0.307 & 0.330 & 0.067 & 0.096 & 0.246 & 0.177 \\
& $\mathrm{n}$ & 0.752 & 0.752 & 0.235 & 0.553 & 0.378 & 0.630 & 0.609 & 0.585 & 0.600 \\
& $\mathrm{~B}$ & 0.999 & 0.998 & 0.997 & 0.999 & 0.984 & 0.945 & 0.995 & 0.999 & 0.999 \\
& $\mathrm{~S}$ & 0.021 & 0.030 & 0.030 & 0.035 & 0.062 & 0.127 & 0.041 & 0.018 & 0.012 \\
\hline
\end{tabular}

The occurrence of the hysteresis loops and consequently the lack of overlapping of flow curves with increasing and decreasing shear rates was a general manifestation of the instability of the tested sludge. Based on the plotted hysteresis loops, it was found that the tested sludge is a thixotropic fluid, with its viscosity depending on the rate and time of shear and decreasing under shear. Partial destruction of the sludge structure is observed with the increase in shear rate, which is reflected by the upper curve of the hysteresis loop, whereas the lower curve represents partial remodeling of the structure at a decreasing shear rate. To graphically illustrate the resulting hysteresis loop, only two graphs are provided for the combinations $C$ and $G$ (Figure 8).

The surface of the hysteresis loop changed dynamically depending on the conditioning combination (Table 4). The untreated sludge was characterized by the lowest area of the hysteresis loop, and thus the highest structure stability (combination $0, \mathrm{~T}=85 \mathrm{~Pa} \cdot \mathrm{s}^{-1}$ ). The dosing of polyelectrolyte into the tested sludge led to an increase in the T-value. An even higher increase in the area of the hysteresis loop was caused by the sequential dosing of chemical reagents PIX-113 and C-494 (combinations C and D). On the other hand, the magnetic field application allowed for an increase in the stability of 
the sludge structure (decrease in the T-value). The smallest area of the hysteresis loop was recorded for the sludge exposed to the magnetic field at a flow rate of $1.0 \mathrm{~L} / \mathrm{min}$ in the opposite direction to the magnetic field lines (combination $\mathrm{G}, \mathrm{T}=105 \mathrm{~Pa} \cdot \mathrm{s}^{-1}$ ).

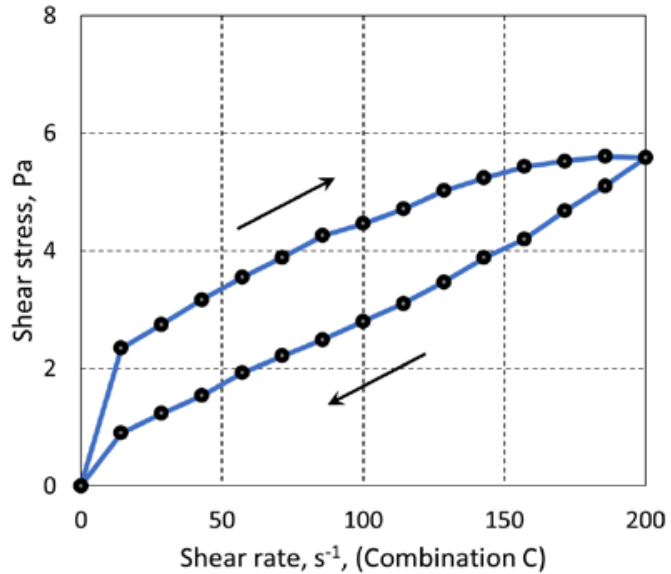

(a)

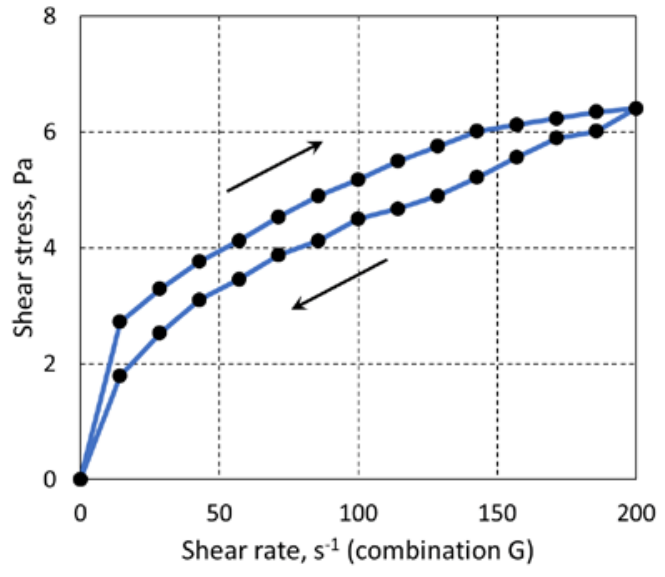

(b)

Figure 8. Area of the hysteresis loop and the index of thixotropy depending on the method of sludge conditioning $(\mathbf{a}, \mathbf{b})$.

Table 4. Sludge compressibility factor depending on the combination of sludge conditioning.

\begin{tabular}{ccccccccc}
\hline \multicolumn{7}{c}{ Combination of Sludge Conditioning } \\
\hline 0 & A & B & C & D & E & F & G & H \\
\hline \multicolumn{8}{c}{ Area of the Hysteresis Loop, T, Pa/s } \\
\hline 85 & 151 & 119 & 270 & 209 & 143 & 189 & 105 & 150 \\
\hline
\end{tabular}

\subsection{Supernatant Contamination}

The conditioning method significantly affected the quality of the supernatant after sludge dewatering by centrifugation. The precondition for obtaining the lowest COD, turbidity, and solids content in the supernatant was the use of dual conditioning, followed by the exposure of sludge in a magnetic field (Figure 9).

The most effective was the application of sludge flow through the coil in the direction opposite to the magnetic field lines (combinations $\mathrm{G}$ and $\mathrm{H}$ ).

The chemical oxygen demand of the supernatant after sludge conditioning with the combination $\mathrm{G}$ was $540 \mathrm{mg} \mathrm{O}_{2} / \mathrm{L}$, whereas in the case of combination A (optimal polyelectrolyte dose), COD was $970 \mathrm{mg} \mathrm{O}_{2} / \mathrm{L}$ (Figure 9).

Sludge conditioning using the combinations $\mathrm{C}, \mathrm{D}$, and $\mathrm{E}$ to $\mathrm{H}$ combinations resulted in a reduction of ammonium and Kjeldahl nitrogen concentration in the supernatant by about $100 \mathrm{mg} / \mathrm{L}$ compared to combination 0-B (Table 5). Similar changes were observed in concentrations of dissolved organic carbon (Table 5). The addition of polyelectrolyte to the sludge led to the reduction of TOC from $319 \mathrm{mg} \mathrm{C} / \mathrm{L}$ (combination 0) to approximately $240 \mathrm{mg} \mathrm{C/L}$ (combinations A and B). Dual chemical conditioning and sludge exposure to the magnetic field $(\mathrm{C}-\mathrm{D}, \mathrm{E}-\mathrm{H})$ resulted in a further reduction of TOC to an average of $160 \mathrm{mg} \mathrm{C} / \mathrm{L}$.

A significant difference was observed in the concentrations of total phosphorus (Figure 10). Combinations of sludge conditioning based on the dosing of PIX-113 and action of the magnetic field led to a significant reduction of phosphorus concentration in the supernatant. The concentration decreased from about $35.0 \mathrm{mg} / \mathrm{L}(0-\mathrm{B})$ to $0.8 \mathrm{mg} / \mathrm{L}(\mathrm{C}-\mathrm{H})$. 


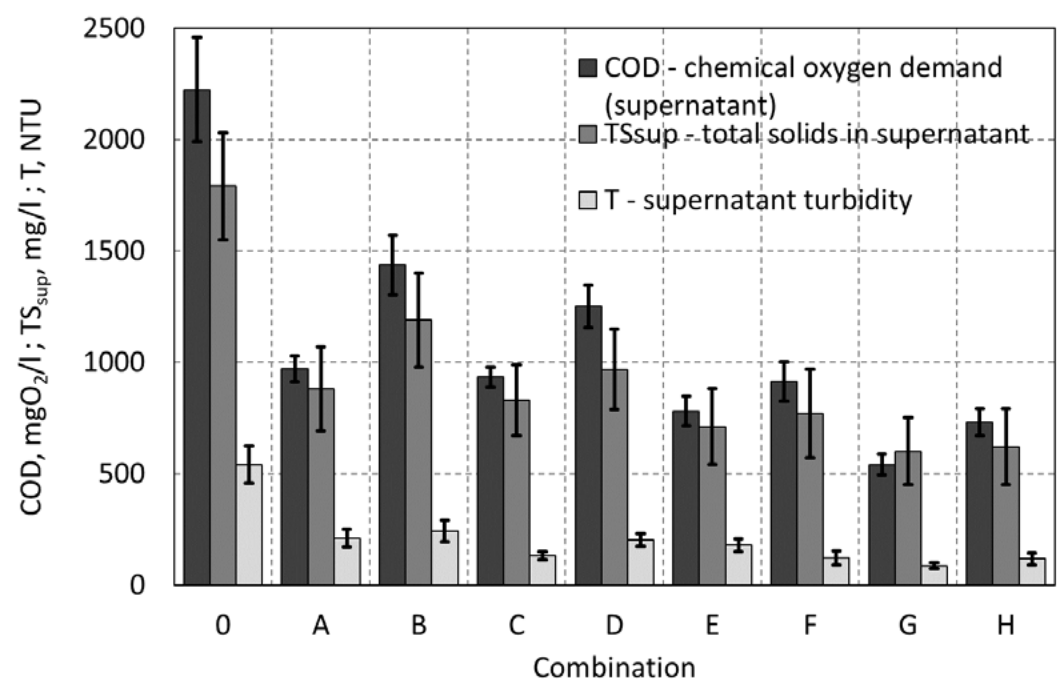

Figure 9. The contamination of sludge supernatant after conditioning and dewatering of the tested sludge.

Table 5. Contents of dissolved forms of carbon and nitrogen in the sludge supernatant.

\begin{tabular}{cccc}
\hline Combination & TKN, $\mathbf{~ g g} / \mathbf{L}$ & $\mathbf{N}^{-N_{H}}{ }^{+}, \mathbf{m g} / \mathrm{L}$ & TOC, $\mathbf{~ g ~ C / L ~}$ \\
\hline 0 & $896 \pm 68$ & $775 \pm 61$ & $319 \pm 40$ \\
\hline A & $868 \pm 104$ & $612 \pm 92$ & $223 \pm 41$ \\
\hline B & $856 \pm 122$ & $674 \pm 86$ & $257 \pm 46$ \\
\hline C & $778 \pm 101$ & $528 \pm 69$ & $148 \pm 25$ \\
\hline D & $767 \pm 117$ & $596 \pm 98$ & $176 \pm 37$ \\
\hline E & $834 \pm 127$ & $645 \pm 106$ & $194 \pm 43$ \\
\hline F & $750 \pm 136$ & $553 \pm 112$ & $181 \pm 40$ \\
\hline G & $722 \pm 94$ & $481 \pm 174$ & $147 \pm 18$ \\
\hline H & $784 \pm 113$ & $601 \pm 82$ & $168 \pm 29$ \\
\hline
\end{tabular}

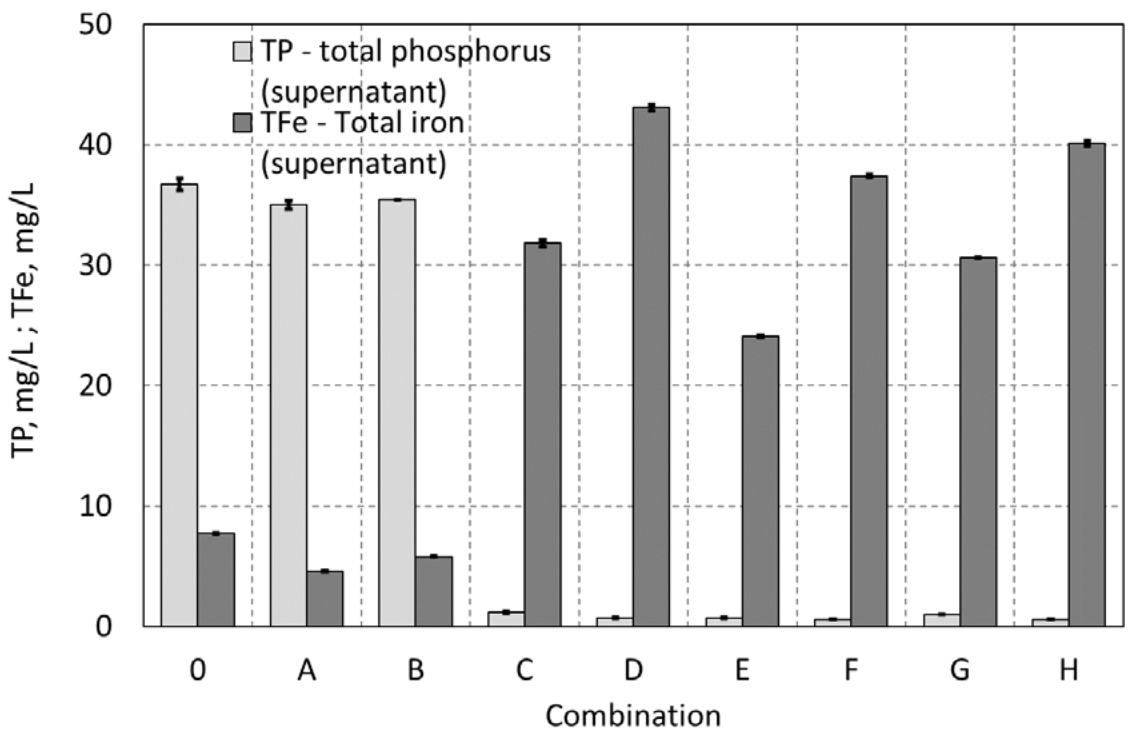

Figure 10. The concentration of total phosphorus and iron in the supernatant. 
The use of iron coagulant $(\mathrm{C}-\mathrm{H})$ in conditioning yielded residual iron concentrations ranging from 30 to $40 \mathrm{mg} \mathrm{Fe} / \mathrm{L}$ in the supernatant (Figure 10). From the point of view of conditioning technology, this means a loss of coagulant of $5 \%$, which ultimately should be considered insignificant.

\section{Conclusions}

The effectiveness of the sludge modification depends on the selection of the most favorable preparation parameters. The condition is the use of a double chemical method and appropriate exposure parameters in the magnetic field (combination G). Comparing the two most favorable combinations of conditioning C (polyelectrolyte) and G (PIX + polyelectrolyte + magnetic field), the advantage of the $\mathrm{G}$ combination was especially evident in the dewaterability (specific resistance to filtration). The improvement in rheological properties and the quality of the supernatant requires further investigation.

The effect of the exposure of conditioned sludge (after the dual chemical method) to the magnetic field depended on two factors. The first factor was the direction of sludge flow through the magnetic field. This was a key factor in improving the efficiency of sludge conditioning using this method. The sludge flow through the solenoid in the direction opposite to the magnetic field had a strong effect on particles. The second factor was the rate of sludge flow through the magnetic field. Low rates of sludge flow through the coil are recommended. Too high a flow rate may lead to the deterioration of filtration efficiency. This may be due to not only the shorter exposure time but also the mechanical destruction of the structure of sludge flocs. Generally, the effect of the magnetic field on sludge conditioning (especially in the triple method: Inorganic coagulant-polyelectrolyte-magnetic field) was complex.

Based on the results, the research on further optimization of sludge conditioning in the magnetic field can be planned. It seems that reducing the flow rate and longer sludge retention in the solenoid intensifies the effect of the magnetic field on particles and sludge structure. It is reasonable to conduct the test with only two factors, i.e., ferric coagulant and the magnetic field. The spectrum of research can be further expanded to include the magnetic properties of the substrate, in particular, through ensuring the presence of diamagnetic, paramagnetic, and ferromagnetic materials.

Author Contributions: T.K. conceived and designed the experiments; T.K. performed the experiments; T.K. analyzed the data; T.K., M.K., and I.Z. contributed reagents/materials/analysis tools; T.K., M.K., and I.Z. wrote the paper. All authors have read and agreed to the published version of the manuscript.

Funding: The scientific research was funded by the statute subvention of Czestochowa University of Technology, Faculty of Infrastructure and Environment.

Conflicts of Interest: The authors declare no conflict of interest.

\section{References}

1. Wolny, L.; Kamizela, T. Technika dezintegracji ultradźwiękowej w technologii ścieków i osadów ściekowych. Ekologia I Technika 2003, 1, 3-7.

2. Skinner, S.; Studer, L.J.; Dixon, D.R.; Hillis, P.; Rees, C.A.; Wall, R.C.; Cavalida, R.G.; Usher, S.P.; Stickland, A.; Scales, P.J. Quantification of wastewater sludge dewatering. Water Res. 2015, 82, 2-13. [CrossRef] [PubMed]

3. Wójcik, M.; Stachowicz, F. Influence of physical, chemical and dual sewage sludge conditioning methods on the dewatering efficiency. Powder Technol. 2019, 344, 96-102. [CrossRef]

4. Mowla, D.; Tran, H.; Allen, D.G. A review of the properties of biosludge and its relevance to enhanced dewatering processes. Biomass-Bioenergy 2013, 58, 365-378. [CrossRef]

5. Qi, Y.; Thapa, K.B.; Hoadley, A.F. Application of filtration aids for improving sludge dewatering properties-A review. Chem. Eng. J. 2011, 171, 373-384. [CrossRef]

6. Wang, Y.L.; Yan, W.L.; Qian, X.; Sheng, Y.Q.; Chen, Y.J. Characterization of flocculation-conditioning ferric hydroxide gelwith differently charged polyacrylamides. J. Water Process Eng. 2015, 7, 102-111. [CrossRef] 
7. Liu, Y.; Wang, L.; Ma, J.; Zhao, X.; Huang, Z.; Mahadevan, G.D.; Qi, J. Improvement of settleability and dewaterability of sludge by newly prepared alkaline ferrate solution. Chem. Eng. J. 2016, 287, 11-18. [CrossRef]

8. Zhen, G.; Lu, X.; Wang, B.; Zhao, Y.; Chai, X.; Niu, D.; Zhao, A.; Li, Y.; Song, Y.; Cao, X. Synergetic pretreatment of waste activated sludge by $\mathrm{Fe}(\mathrm{II})$-activated persulfate oxidation under mild temperature for enhanced dewaterability. Bioresour. Technol. 2012, 124, 29-36. [CrossRef]

9. Shi, Y.; Yang, J.; Yu, W.; Zhang, S.; Liang, S.; Song, J.; Xu, Q.; Ye, N.; He, S.; Yang, C.; et al. Synergetic conditioning of sewage sludge via $\mathrm{Fe} 2+$ /persulfate and skeleton builder: Effect on sludge characteristics and dewaterability. Chem. Eng. J. 2015, 270, 572-581. [CrossRef]

10. Ciborowski, M.; Hrut, K.; Kamizela, T.; Kowalczyk, M.; Potiomkin, K. Dual conditioning of sewage sludge with coagulant and polyelectrolyte. Forum Exploiter. Instal 2014, 3, 34-36. (In Polish)

11. Łuszczek, B. The problem of nitrogen and phosphorus return charges in leachate from sludge dewatering on the example of Krakow sewage treatment plants. Instal 2014, 4, 47-51. (In Polish)

12. Cibrowski, M.; Potiomkin, K.; Hrut, K.; Kowalczyk, M.; Kamizela, T. Dualne kondycjonowanie osadów ściekowych koagulantem i polielektrolitem. Instal 2014, 4, 57-59.

13. Yavuz, H.; Çelebi, S.S. Effects of magnetic field on activity of activated sludge in wastewater treatment. Enzym. Microb. Technol. 2000, 26, 22-27. [CrossRef]

14. Tomska, A.; Wolny, L. Enhancement of biological wastewater treatment by magnetic field exposure. Desalination 2008, 222, 368-373. [CrossRef]

15. Zaidi, N.S.; Sohaili, J.; Muda, K.; Sillanpää, M. Magnetic Field Application and its Potential in Water and Wastewater Treatment Systems. Sep. Purif. Rev. 2013, 43, 206-240. [CrossRef]

16. Wang, Z.; Liu, X.; Ni, S.-Q.; Zhang, J.; Zhang, X.; Ahmad, H.A.; Gao, B. Weak magnetic field: A powerful strategy to enhance partial nitrification. Water Res. 2017, 120, 190-198. [CrossRef]

17. Łebkowska, M.; Narożniak, A.R.; Pajor, E.; Pochanke, Z. Effect of a static magnetic field on formaldehyde biodegradation in wastewater by activated sludge. Bioresour. Technol. 2011, 102, 8777-8782. [CrossRef]

18. Hrut, K.; Kamizela, T. Changes in filtration properties of digested sludge under the influence of magnetic field. Desalin. Water Treat. 2018, 117, 282-289. [CrossRef]

19. Zieliński, M.; Rusanowska, P.; Dębowski, M.; Hajduk, A. Influence of static magnetic field on sludge properties. Sci. Total Environ. 2018, 625, 738-742. [CrossRef] [PubMed]

20. Hrut, K.; Kamizela, T. Iron compounds and a magnetic field as the conditioning agents for municipal sewage sludge. E3S Web Conf. EDP Sci. 2018, 45, 00022. [CrossRef]

21. COMSOL ${ }^{\circledR}$ SOFTWARE VERSION 5.2a. Available online: https://www.comsol.com/product-update/5.2a (accessed on 15 January 2020).

22. Gilcreas, F.W. Future of standard methods for the examination of water and wastewater. Health Lab. Sci. 1967, 4, 137-141. [PubMed]

23. The Authority of the Standards Policy and Strategy Committee. Characterization of Sludge-Filtration Properties, Part 1: Capillary Suction Time (CST); PN-EN 14701-1:2007; BSI: London, UK, 2007. (In Polish)

24. The Authority of the Standards Policy and Strategy Committee. Characterization of Sludge-Filtration Properties, Part 2: Determination of Specific Resistance to Filtration; PN-EN 14701-2:2013-07; BSI: London, UK, 2013. (In Polish)

25. The Authority of the Standards Policy and Strategy Committee. Characterization of Sludge-Filtration Properties, Part 3: Determination of the Compressibility; PN-EN 14701-3:2007; BSI: London, UK, 2007. (In Polish)

26. Malkin, A.Y.; Isayev, A.I. Rheology. Concepts, Methods, and Applications, 2nd ed.; ChemTec Publishing: Toronto, ON, Canada, 2011.

27. ISO, ČSNEN. Determination of Selected Elements by Means of Optical Emission Spectrometry with Inductively Excited Plasma (ICP-OES); BS-EN 11885:2009; BSI: Warsaw, Poland, 2009.

(C) 2020 by the authors. Licensee MDPI, Basel, Switzerland. This article is an open access article distributed under the terms and conditions of the Creative Commons Attribution (CC BY) license (http://creativecommons.org/licenses/by/4.0/). 